http://dx.doi.org/10.5007/2175-8085.2017v20n1p36/

\title{
A demanda por previdência privada no Brasil: uma análise empírica
}

The demand for private pension in Brazil: an empirical approach

\author{
Patrícia Romualdo de Almeida \\ patriciaromualdo@usp.br \\ Universidade Federal de Minas Gerais \\ (UFMG)
}

\author{
Thiago Costa Soares \\ thiago.costa@ufjf.edu.br \\ Universidade Federal de Juiz de Fora \\ (UFJF-GV)
}

Resumo: A expectativa de vida do brasileiro aumentou nos últimos anos e a necessidade de manter o padrão de consumo vem expandindo o número de investimentos em fundos de pensão privados. Com efeito, entender melhor os atributos que impulsionam a demanda por esse produto é condição necessária para planejar o segmento. Nesse sentido, o objetivo desse estudo foi analisar os determinantes socioeconômicos da escolha individual em investir na previdência privada no Brasil. Para tanto, ajustou-se uma regressão logística a dados da PNAD 2011. Os resultados revelam, como esperado, que a renda, a escolaridade e a idade influenciam positivamente a probabilidade de aquisição do produto. Além dessas variáveis, constatou-se também que homens e residentes da região sudeste apresentam maiores chances de investir nesse fundo. Evidentemente, concluiu-se que os gestores, públicos e privados, devem planejar o futuro da previdência levando em consideração a tendência de crescimento da renda e escolaridade do brasileiro, bem como o envelhecimento da população.

Palavras-chave: Previdência privada; Brasil; logit

\begin{abstract}
The life expectancy in Brazil rose steeply over in recent years and the number of investments in private pension have been on the rise. In fact, better understanding the attributes that drive the demand for this product is a necessary condition for planning the segment. In this sense, this study aims to analyze the socioeconomic determinants of the individual choice to invest in private funds in Brazil. For this, a logistic regression was estimated to PNAD 2011 data. The mains results revel, as expected, that income, schooling and age positively influence the probability of product acquisition. In addition, it was also found that men and residents of the Southeast in Brazil have greater chance of investing. Hence, we concluded that public and private managers should plan the future of social security take into account the growth trend of income and education, as well as the population aging.
\end{abstract}

Keywords: Private Pension, Brazil, logit

\section{INTRODUÇÃO}

A expectativa de vida do brasileiro tem aumentado consideravelmente e a necessidade individual de manter o padrão estável de consumo no longo prazo faz com que muitas pessoas invistam nos fundos de previdência privados, uma vez que, muitas vezes, a previdência social não garante a manutenção do bem-estar quando o indivíduo se aposenta (COELHO; CAMARGOS, 2012). 
Segundo o projeto National Transfer Accounts, da Universidade da Califórnia, os custos com a aposentadoria pública não serão acompanhados pelo aumento das receitas do Estado no Brasil. Na ausência de uma reforma previdenciária, a produtividade da previdência, medida pelo número total arrecadado sobre os custos sociais, será cerca $30 \%$ menor em 2050 em relação a 2010 (STEFANO, 2011).

Coelho e Camargos (2012), em seu estudo sobre os determinantes para a expansão do setor previdenciário privado, afirmam que o poder de compra do benefício fornecido pelo Instituto Nacional de Seguro Social (INSS) foi decrescente para os indivíduos que recebem salários superiores ao mínimo. Segundo os autores, considerando a inflação acumulada pelo IGP-M, de 1997 a 2011, os reajustes reais no benefício previdenciário chegaram a 58\% para as pessoas que receberam até um salário mínimo, ao passo que os demais tiveram uma perda de $23 \%$, em média.

Por esse motivo, no Brasil, os fundos de investimento têm crescido significativamente com o intuito de oferecer renda complementar à população (LIMA, 2006). Um exemplo concreto foi a mudança da receita do segmento que, segundo a Federação Nacional de Previdência Privada e Vida (FENAPREVI), expandiu no período 2010-2011, onde a contribuição em 2011 (R \$ 53,6 bilhões) registrou 16,26\% de aumento em relação a 2010 (R\$ 46,1 bilhões).

Embora seja assunto relevante ao planejamento previdenciário nacional, o Brasil ainda carece de estudos com microdados sobre a demanda por fundos de pensão e seus principais determinantes. Nesse sentido, o objetivo geral deste estudo foi analisar os determinantes da escolha individual em investir na previdência privada no Brasil, considerando um conjunto de variáveis socioeconômicas. Esta pesquisa levanta importantes informações, pois cria uma medida de probabilidade de investimento associada a atributos individuais.

Além desta introdução, este estudo está organizado em outras quatro seções. A segunda seção descreve sobre os sistemas de previdência no Brasil, público e privado. A terceira seção reporta os procedimentos metodológicos. A quarta apresenta e discute os principais resultados. E na quinta, e última seção, conclui-se acerca do tema.

\subsection{O SISTEMA PÚBLICO DE PREVIDÊNCIA BRASILEIRO}

A previdência social brasileira teve início em 1923 com as Caixas de Aposentadorias e pensões (CAPs), que foram substituídas a partir de 1933 por Institutos de Aposentadorias e 
Pensões (IAPs) de diversas categorias, até que em 1966, todas as IAPs se fundiram dando início ao Instituto Nacional de Previdência Social (INPS). Na sequência da história, em 1990, o INPS se fundiu ao Instituto de Administração Financeira da Previdência e Assistência Social (IAPAS) para formar, o então em vigor, Instituto Nacional da Seguridade Social (INSS).

É importante ressaltar que a previdência social se financia basicamente com recursos sobre a folha de pagamento, cobrados tanto dos empregados quanto dos empregadores, repasses da União, receitas provenientes de transações patrimoniais, bem como receitas de aplicações financeiras. Os recursos cobrados sobre a folha de pagamento, de acordo com Weintraub (2005), têm natureza tributária.

Em termos de cobertura, a previdência social apenas remunera com o valor integral dos rendimentos recebidos enquanto na ativa os trabalhadores de baixa renda. No caso da chamada classe média, a remuneração concedida pela previdência é inferior à remuneração que era obtida enquanto na ativa, ou seja, os trabalhadores que não se enquadram como baixa renda não conseguem manter o nível de vida na velhice apenas com os rendimentos de aposentadoria (COELHO; CAMARGOS, 2012).

Porém, é de notório saber que a previdência pública vem acumulando déficits ao longo do tempo. Zylberstajn, Afonso e Souza (2006) destacam que devido a uma série de razões históricas e institucionais, o sistema previdenciário brasileiro ainda está longe do equilíbrio atuarial, embora já tenha passado por algumas reformas. Para se ter uma noção da evolução do déficit, Carvalho e Murgel (2007) apontam que a relação entre contribuintes e beneficiários, que em 1950 era de 8 contribuintes para cada beneficiário, em 1997 passou a ser de 1,7 contribuintes.

Em um estudo realizado em 2003, Ellery Jr. e Bugarin (2005) mostraram que para financiar um regime de aposentadoria integral, uma contribuição sobre a folha de pagamento de aproximadamente $15 \%$ seria suficiente, a despeito da contribuição média paga pelas empresas de $22 \%$, acrescida de mais $10 \%$ pagos pelos empregados. Mesmo assim, o caixa do INSS ainda se encontra em déficit, sendo possíveis razões para essa situação o custeamento de programas de assistência social pela previdência, sobretudo após a Constituição Federal de 1988, e também o fato de a idade média de aposentadoria dos brasileiros ter sido relativamente baixa até períodos recentes.

Tafner (2007), ao comparar as regras de concessão de benefícios previdenciários, referentes à aposentadoria e pensão, do Brasil com outros 20 países (sendo 10 do continente europeu, 6 do continente americano e 4 da Ásia), observou que, em termos gerais, o Brasil foi Recebido em: 03-08-2017; Revisado em: 12-10-2017; Aceito em: 25-10-2017 
o país a apresentar regras menos restritivas em termos de concessão de aposentadorias. Até então, não havia limite mínimo de idade para se aposentar, sendo necessário apenas o cumprimento de 35 anos de contribuições no caso de homens e 30 anos no caso de mulheres. Embora atualmente essa regra já tenha sido suprimida e tenham sido estabelecidos limites de idade para aposentadoria, os déficits que se acumularam ainda remanescem.

Coelho e Camargos (2012) apontam também que fatores relacionados a problemas de improbidade na gestão, fraudes (internas e externas) e sonegações fazem parte do histórico do sistema previdenciário brasileiro e, certamente, contribuem para o agravamento do déficit.

A trajetória demográfica da população brasileira é outro fator que ajuda a compreender o déficit previdenciário no país. De acordo com Coelho e Camargos (2012), o regime financeiro da previdência pública brasileira é o de repartição, isto é, os pagamentos aos aposentados são custeados pelas contribuições dos trabalhadores em atividade, sendo, dessa forma, profundamente afetado por questões demográficas. Considerando que a taxa de fecundidade brasileira, de acordo com o Censo de 2010, foi de 1,86 filhos por mulher, parte do desequilíbrio do sistema previdenciário pode ser atribuída ao nível de reposição da população, que deveria ser de, no mínimo, 2,1 filhos por mulher.

Esse problema não é exclusivo do Brasil. A forma de financiamento da previdência social é uma questão que atinge muitos outros países, sobretudo no que tange as mudanças demográficas. De acordo de Ellery Jr. e Bugarin (2005), estudos indicam que os sistemas previdenciários de países europeus, do Japão e dos Estados Unidos deverão enfrentar problemas até o ano de 2030, de modo que o equilíbrio do sistema previdenciário será essencial para a organização das contas públicas.

O sistema brasileiro de previdência compreende não somente o Regime Geral de Previdência Social (RGPS). De acordo com Coelho e Camargos (2012), esse sistema se sustenta em três pilares: (i) RGPS, de natureza pública e de filiação obrigatória para os trabalhadores regidos pela Consolidação das Leis do Trabalho (CLT), operado pelo INSS e sob o regime financeiro de caixa; (ii) Regimes Próprios de Previdência de Servidores, de natureza pública e de filiação exclusiva e obrigatória para os servidores públicos titulares de cargos efetivos da União, dos Estados, do Distrito Federal e dos Municípios, operados, geralmente, sob o regime financeiro de caixa; e (iii) regime de Previdência Complementar, de natureza privada, contratual, com filiação facultativa, autônomo em relação ao RGPS e aos regimes próprios dos servidores públicos, e operado sob o regime financeiro de capitalização. A seção seguinte foi destinada ao Regime de Previdência Complementar. 


\subsection{O SISTEMA DE PREVIDÊNCIA PRIVADA BRASILEIRO}

O sistema de previdência privada brasileiro, cuja denominação mais adequada é previdência complementar, surgiu para atender necessidades de pessoas que não tinham a previdência pública como uma alternativa viável para manutenção do nível de vida após a aposentadoria, ou que não confiavam no sistema previdenciário público, devido às fragilidades já apontadas na seção anterior.

A previdência complementar foi dividida pela Lei $\mathrm{n}^{\circ}$. $6.435 / 77$ em previdência complementar aberta e previdência complementar fechada, sendo regidas até 2001, respectivamente, pelo Decreto $n^{\circ} .81 .402 / 78$ e pelo Decreto $n^{\circ}$. 81.240/78. A partir de 2001, essas entidades passaram a ser regidas pela Lei Complementar $n^{\circ}$. 109/01. Além disso, a Lei Complementar $n^{\circ}$. 108/01, dispõe sobre a relação entre a União, os Estados, o Distrito Federal e os Municípios, suas autarquias, fundações, sociedades de economia mista e outras entidades públicas e suas respectivas Entidades Fechadas de Previdência Complementar (EFPC).

O sistema de previdência complementar é operado pelas entidades previdenciárias, cujo objetivo principal é a instituição e execução de planos de benefícios previdenciários. $\mathrm{O}$ que diferencia a previdência complementar aberta da fechada é o vínculo entre a entidade de previdência e o beneficiário. Ao contrário da previdência aberta, na previdência fechada é obrigatória a existência de vínculo empregatício entre o participante e a entidade de classe patrocinadora do fundo, ou de vínculo associativo entre o participante e a entidade de classe instituidora do fundo. Além disso, a entidade fechada de previdência complementar (EFPC) não pode possuir finalidade lucrativa e seus planos devem ser concedidos de forma universal a todos os seus empregados, associados ou membros (CARVALHO; MURGEL, 2007).

As atividades da EFPC são de competência do Ministério da Previdência e Assistência Social (MPAS), através da Secretaria de Previdência Complementar (SPC). Já as Entidades Abertas de Previdência Complementar (EAPCs) são de competência do Ministério da Fazenda, por intermédio da Superintendência Nacional de Seguros Privados (SUSEP).

Os planos de previdência privada no Brasil se beneficiam de postergação do Imposto de Renda (IR), de modo que pode haver a isenção de IR na fase de acumulação dos recursos, nesse caso, sendo tal imposto cobrado somente quando do recebimento dos benefícios de aposentadoria pelo contribuinte. De acordo com Gaudenzi (2008), esse benefício tributário tem como objetivo incentivar a adesão de pessoas aos planos privados, na tentativa de alcançar o equilíbrio social, no sentido da manutenção do padrão econômico na aposentadoria, sem afetar de sobremaneira a arrecadação tributária. 
No que diz respeito aos planos, as previdências complementares, aberta e fechada, também se diferenciam. Em relação à previdência aberta, os planos mais conhecidos são: (a) Plano Gerador de Benefícios Livres (PGBL); e (b) Vida Gerador de Benefícios Livres (VGBL). A diferença entre o PGBL e o VGBL é principalmente na tributação de IR. Enquanto os titulares do plano PGBL podem deduzir até $12 \%$ da remuneração da pessoa física para efeitos de IR durante o período de acumulação dos recursos, no plano VGBL tal isenção não ocorre nessa fase, somente na fase de recebimento do benefício é que os titulares dos planos VGBL gozam dessa isenção fiscal (tal benefício não se estende a ganhos provenientes de aplicações financeiras).

No caso da previdência fechada, existem três possibilidades de planos, que são normatizados pela Resolução do Conselho de Gestão de Previdência Complementar - CGPC n. ${ }^{\circ}$ 16/05: (a) Benefício Definido (BD); (b) Contribuição Definida (CD); e (c) Contribuição Variável (CV). No Plano BD são previamente definidos o valor ou nível dos benefícios programados, sendo os custos determinados de forma atuarial, visando assegurar sua concessão e manutenção. No plano $\mathrm{CD}$, o valor dos benefícios programados é ajustado constantemente ao saldo de conta mantido pelo participante. Por fim, o plano CV conjuga as características dos outros dois planos (COELHO; CAMARGOS, 2012).

Conhecidas as principais características dos planos de previdência complementar, a seguir são expostos a metodologia e os dados que foram necessários na condução deste trabalho, cujo objetivo é a investigação dos determinantes individuais para investimento em planos de previdência privada no Brasil.

\section{METODOLOGIA 3.1. MODELO EMPÍRICO}

A decisão em investir na previdência privada possui um caráter qualitativo baseado na utilidade individual. Para exemplificar, sejam $U_{i}\left(P V_{i}\right)$ a utilidade do indivíduo $i \quad(i=$ $1,2, \ldots, n)$ quando se adquire fundos de pensão e $U_{i}\left(1-P V_{i}\right)$, a utilidade de $i$ no contexto onde a previdência social é a única forma de obter rendimentos após se aposentar. As expressões $U_{i}\left(P V_{i}\right)$ e $U_{i}\left(1-P V_{i}\right)$ são crescentes quanto ao retorno financeiro esperado, mas decrescentes em relação ao custo da aquisição do plano. Assim, o indivíduo $i$ deverá optar por investir se $\left.U_{i}\left(P V_{i}\right) \succ \quad{ }^{\top} V_{i}\right)$. Em outras palavras, o público decide comprar planos de 
pensão privados quando os retornos líquidos dessa modalidade são mais elevados que os retornos da previdência social, os quais são limitados por decreto.

Contudo, as utilidades são variáveis latentes (não observáveis) e, neste caso, verificase somente se determinado indivíduo adquiriu ou não o fundo de pensão, decisão que pode ser representada por uma variável binária:

$$
\begin{aligned}
& P V_{i}=1, \text { se o indivíduo investiu; } \\
& P V_{i}=0, \text { se o indivíduo não investiu. }
\end{aligned}
$$

Tal decisão, por sua vez, está associada a atributos que aumentam a probabilidade da aquisição. Formalmente,

$$
p_{i}=p\left(P V_{i}=1\right)=f\left(X_{i} \beta\right)
$$

em que a probabilidade de escolher investir em um fundo de pensão $p\left(P V_{i}=1\right)$ é uma função de um vetor de variáveis explicativas $X_{i}$, tais como renda, escolaridade, sexo, idade, etnia e um conjunto de variáveis categóricas indicando a região do indivíduo; $\beta$ é um vetor de parâmetros a ser estimado por meio de uma função de distribuição de probabilidade $f$ conhecida.

No caso de modelos de probabilidade cuja variável dependente é categórica, como no presente estudo, o ajuste do modelo por Mínimos Quadrados Ordinários (MQO), método bastante difundido na literatura, torna-se inadequado. Primeiro, o procedimento não impõe a restrição $0 \leq p\left(P V_{i}\right) \leq 1$, podendo ocorrer estimativas da probabilidade maiores que a unidade. Além disso, as variáveis explanatórias relacionam-se sempre de maneira linear com a dependente, a não ser que se incluam termos quadráticos. Ademais, estimações por MQO neste contexto produzem erros heterocedásticos ${ }^{1}$ e não normais ${ }^{2}$ (MADDALA, 1986).

Por essas razões, o modelo ajustado neste estudo supõe que $f\left(X_{i} \beta\right)$ assuma uma função de distribuição logística $f\left(X_{i} \beta\right)=e^{-X_{i} \beta} / 1+e^{-X_{i} \beta}$ em que a probabilidade de observar a escolha dos indivíduos é maximizada por uma função de verossimilhança. A equação principal se inicia com a expressão (2):

$$
f\left(P V_{1}, P V_{2}, \ldots, P V_{n}\right)=\prod_{1}^{n} f_{i}\left(P V_{i}\right)=\prod_{1}^{n} P_{i}^{P V_{i}}\left(1-P_{i}\right)^{l-P V_{i}},
$$

\footnotetext{
${ }^{1}$ Modelos heterocedásticos produzem estimadores ineficientes, isto é, não possuem variância mínima na classe dos estimadores não tendenciosos (MADDALA, 1986).

${ }^{2}$ A normalidade dos resíduos é condição importante na inferência estatística dos parâmetros no método de MQO (GREENE, 2003).

Recebido em: 03-08-2017; Revisado em: 12-10-2017; Aceito em: 25-10-2017
} 
em que PV é a escolha individual pela aquisição de planos de previdência privados. A função de densidade de probabilidade conjunta pode ser escrita a partir das funções individuais, pois a decisão de cada indivíduo segue a função de densidade logística. Formalmente, a função de verossimilhança logarítmica (FVL) descreve-se do seguinte modo:

$$
\begin{gathered}
f\left(P V_{1}, P V_{2}, \ldots, P V_{n}\right)=\sum_{i}^{n}\left[P V_{i} \ln P_{i}+\left(1-P V_{i}\right) \ln \left(1-P_{i}\right)\right], \\
f\left(P V_{1}, P V_{2}, \ldots, P V_{n}\right)=\sum_{i}^{n}\left[P V_{i} \ln P_{i}+\ln \left(1-P_{i}\right)-P V_{i} \ln \left(1-P_{i}\right)\right], \\
f\left(P V_{1}, P V_{2}, \ldots, P V_{n}\right)=\sum_{i}^{n}\left[P V_{i} \ln \left(p_{i} / 1-p_{i}\right)+\ln \left(1-p_{i}\right)\right], \\
f\left(P V_{1}, P V_{2}, \ldots, P V_{n}\right)=\sum_{i}^{n}\left[P V_{i} \ln \left(p_{i} / 1-p_{i}\right)\right]+\sum_{i}^{n} \ln \left(1-p_{i}\right) .
\end{gathered}
$$

Uma vez que $p_{i}=e^{-X_{i} \beta} / 1+e^{-X_{i} \beta}$ e $1-p_{i}=1 / 1+e^{-X_{i} \beta}$, o logaritmo da razão das probabilidades pode ser escrito por $\ln \left(p_{i} / 1-p_{i}\right)=X_{i} \beta$. Logo, a FVL pode ser representada por:

$$
f\left(P V_{1}, P V_{2}, \ldots, P V_{n}\right)=\sum_{i}^{n}\left[P V_{i}\left(X_{i} \beta\right)\right]-\sum_{i}^{n} \ln \left(1+e^{-X_{i} \beta}\right) .
$$

Em (5), a FVL depende do vetor de parâmetros $\beta$. O objetivo torna-se a maximização da FVL, de modo a obter soluções numéricas para os estimadores com a mais alta probabilidade possível de se verificar indivíduos que adquiriram planos de previdência privados.

Nesta pesquisa, o logaritmo da razão de chances é descrito por:

$$
\ln \left(\frac{p_{i}}{1-p_{i}}\right)=\beta_{1}+\beta_{2} Y+\beta_{3} E+\beta_{4} S X+\beta_{5} I+\beta_{6} R+\beta_{7} N+\beta_{8} N O+\beta_{9} S+\beta_{10} C O+\varepsilon_{i},
$$

em que $Y$ é a renda individual, medida em $\mathrm{R} \$ 1.000,00 ; E$, é a escolaridade em anos de estudo; $S X$, é uma variável categórica que representa o sexo do indivíduo, sendo 1 equivalente ao sexo masculino, e 0 , ao feminino; $I$, é a idade; $R$, é a etnia que diferencia os brancos $(\mathrm{R}=1)$ dos não brancos $(\mathrm{R}=0)$. $N, N O, S$ e $C O$ são variáveis dummies incluídas no modelo para captar possíveis diferenças na probabilidade de investir em fundos de pensão por grandes regiões, tendo como base a região sudeste (SE), a qual foi excluída do modelo para evitar o problema referente à armadilha das variáveis dummies ${ }^{3}$. Por último, $\varepsilon_{i}$ representa o erro aleatório, que possui distribuição logística, com média zero e variância constante.

No modelo logit, as estimativas ficam no intervalo [0,1] e as probabilidades estimadas se relacionam não linearmente com as variáveis explicativas. O coeficiente de inclinação de um regressor mede a variação no logaritmo da chance a favor da escolha individual em investir na previdência privada, dada por uma mudança unitária no seu valor, mantidos os

\footnotetext{
${ }^{3}$ Para mais detalhes, ver Greene (2003).

Recebido em: 03-08-2017; Revisado em: 12-10-2017; Aceito em: 25-10-2017
} 
demais regressores constantes. Para cada variável explicativa, as variações da probabilidade (efeitos marginais) podem ser obtidas por $\hat{\beta}\left(1-\hat{p}_{i}\right) \hat{p}_{i}$ (MADDALA, 1986).

\subsection{DADOS}

Os dados dessa pesquisa foram extraídos da Pesquisa Nacional por Amostra de Domicílios (PNAD), ano de 2011, cuja fonte é o Instituto Brasileiro de Geografia e Estatística (IBGE). A amostra inicial da PNAD 2011 foi composta de 358.919 indivíduos. Desse montante, se excluiu 53.184 indivíduos por não terem apresentado informação relativa ao investimento em previdência privada. Excluiu-se também 141.381 indivíduos por não terem declarado renda, ou por terem apresentado renda com valores exorbitantes, caracterizando erros no processo de coleta dos dados. Além disso, se excluiu mais 12.621 indivíduos cuja renda declarada foi zero, por não ser de interesse deste estudo pessoas sem renda. Portanto, a amostra final foi composta de 151.331 indivíduos que responderam às questões referentes às variáveis cruciais propostas neste estudo ${ }^{4}$.

Assim, a Tabela 1 apresenta as variáveis que foram extraídas da PNAD 2011 para suprir a proposta do modelo apresentado na subseção anterior. Tal tabela apresenta as variáveis, sigla, nomenclatura da PNAD e unidade de medida.

Tabela 1 - Descrição das variáveis, PNAD 2011

\begin{tabular}{|c|c|c|c|}
\hline Variável & Sigla & Variável PNAD & $\begin{array}{c}\text { Unidade de medida } \\
\text { PNAD }\end{array}$ \\
\hline Previdência Privada & $P V$ & $\begin{array}{l}\text { V9120 (Era contribuinte de alguma } \\
\text { entidade de previdência privada, no mês } \\
\text { de referência) }\end{array}$ & $\begin{array}{l}2=\operatorname{sim} ; 4=\text { não; }=\text { não } \\
\text { aplicável }\end{array}$ \\
\hline Renda & $Y$ & $\begin{array}{l}\text { V4719 (Rendimento mensal de todos os } \\
\text { trabalhos para pessoas de } 10 \text { anos ou } \\
\text { mais de idade) }\end{array}$ & $\begin{array}{l}\text { Valor em R\$; } 999999 \\
999999=\text { sem } \\
\text { declaração; . = não } \\
\text { aplicável) }\end{array}$ \\
\hline Escolaridade & $E$ & $\begin{array}{l}\text { V4803 (Anos de estudo - todas as } \\
\text { pessoas) }\end{array}$ & $\begin{array}{l}1=\text { Sem instrução e } \\
\text { menos de } 1 \text { ano; } 2=1 \\
\text { ano; } 3=2 \text { anos; } \\
\text { 4=3anos; } 5=4 \text { anos; } \\
6=5 \text { anos; } 7=6 \text { anos; } \\
8=7 \text { anos; } 9=8 \text { anos; } \\
10=9 \text { anos; } 11=10 \\
\text { anos; } 12=11 \text { anos; } \\
13=12 \text { anos; } 14=13\end{array}$ \\
\hline
\end{tabular}

\footnotetext{
${ }^{4}$ É importante destacar que a PNAD adota um plano estratificado e conglomerado com um, dois ou três estágios de seleção, não se caracterizando como amostra aleatória com reposição (amostra complexa). Por isso, adotou-se nesta pesquisa procedimentos que consideram os pesos amostrais das estratificações baseados no número de domicílios. Para mais detalhes, ver Moraes, Moreira e Luiz (2012).

Recebido em: 03-08-2017; Revisado em: 12-10-2017; Aceito em: 25-10-2017
} 


\begin{tabular}{|c|c|c|c|}
\hline & & & $\begin{array}{l}\text { anos; } 15=14 \text { anos; } \\
16=15 \text { anos ou mais; } \\
\text { 17=Não determinados; } \\
=\text { =não aplicável) }\end{array}$ \\
\hline Sexo & $S X$ & V0302 & $\begin{array}{l}2=\text { masculino; } \\
4=\text { feminino }\end{array}$ \\
\hline Idade & $I$ & $\begin{array}{l}\text { V8005 (Idade do morador na data de } \\
\text { referência) }\end{array}$ & idade em anos \\
\hline Etnia & $R$ & V0404 (Cor ou raça) & $\begin{array}{l}2=\text { Branca; } 4=\text { Preta; } \\
\text { 6=Amarela; } 8=\text { =arda; } \\
\text { 0=Indígena; } 9=\text { sem } \\
\text { declaração }\end{array}$ \\
\hline Estados & UF & UF & Unidades de Federação \\
\hline
\end{tabular}

Fonte: Elaboração própria, baseada nas informações da PNAD 2011 (IBGE 2013)

É importante destacar que algumas das variáveis precisaram ser modificadas. Por exemplo, a variável "UF" constante da PNAD foi transformada em dummies regionais. A variável "Etnia" foi transformada em dummy, sendo que 1 representou os indivíduos brancos e 0 os não brancos. Na variável binária "Sexo", masculino passou a ser representado por 1 e feminino por 0. O mesmo ocorreu com a variável "Previdência Privada", em que 1 passou a representar os indivíduos que investiram e 0 aqueles que não investiram. Por fim, a variável escolaridade foi alterada de modo que os indivíduos com menos de 1 ano de instrução fossem considerados sem instrução (0 anos) e os que tinha 15 anos ou mais, foram considerados indivíduos com 15 anos de instrução.

\section{RESULTADOS E DISCUSSÕES}

Primeiramente, é importante destacar os aspectos descritivos dos indivíduos que fizerem parte da amostra. No total, foram incluídos de 151.331 observações referentes às pessoas entrevistadas na PNAD 2011 que se encaixavam no perfil desejado. Desse total, apenas 5.451 afirmaram investir na previdência privada, o que representa 3,6\% da amostra. Em relação às regiões do país, a maioria que investe nos fundos de pensão está situada no Sudeste $(36,36 \%)$. A Figura 1 apresenta o percentual da participação nos fundos de pensão por regiões. 


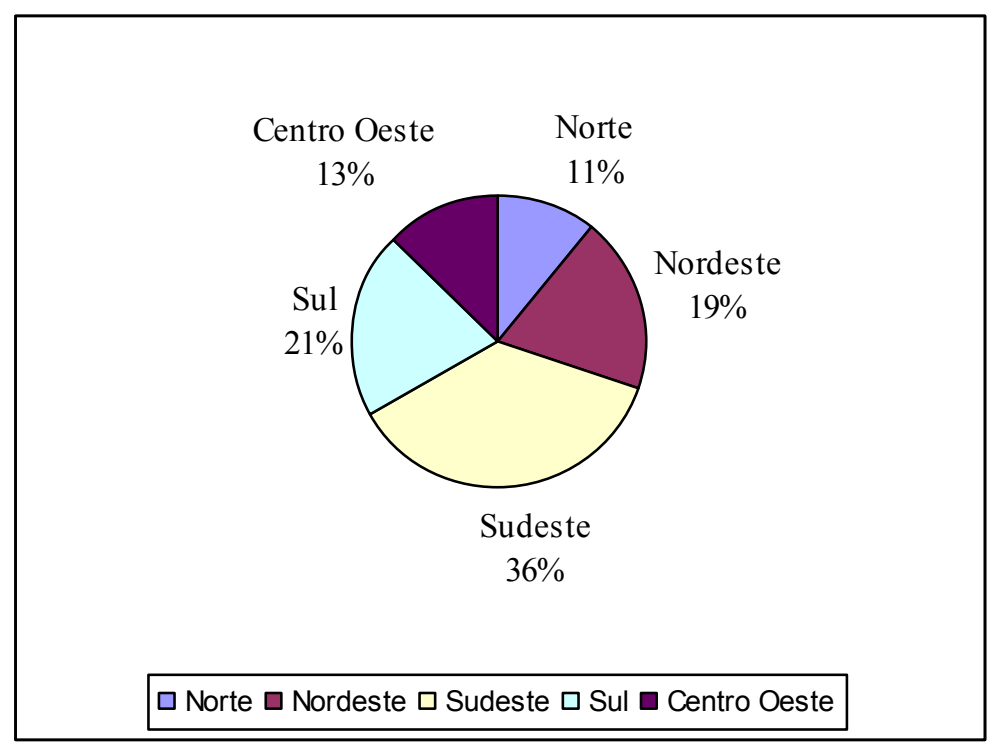

Figura 1: Participação nos fundos de pensão por regiões do país Fonte: Resultados da pesquisa

Além do Sudeste, destacam-se as regiões Sul (20,75\%) e Nordeste (19,1\%). Em termos relativos, a região Norte $(11,14 \%)$ é a que possui o menor número de pessoas que contribuem para a previdência privada. O Centro-Oeste (12,66\%) ocupa posição intermediária.

A renda média dos indivíduos que investem nos fundos de pensão foi de R $\$ 1.452,46$, ao passo que a média dos que não investem girou em torno de $\mathrm{R} \$ 1.247,27$. Outro dado relevante diz respeito à diferença na escolaridade média dos investidores (cerca de 12 anos de estudo) e não investidores (cerca de 8 anos de estudo). Em linhas gerais, os indivíduos que investem em fundos de pensão têm escolaridade média acima da dos demais. Com relação à idade, pode-se observar que estes são indivíduos cuja média etária está entre 39 e 40 anos de idade. Aproximadamente $61,88 \%$ dos indivíduos que pagam plano complementar de renda responderam ser brancos, enquanto $38,12 \%$ declararam ser não brancos. Cabe ressaltar também que 45,75\% da amostra total (incluindo indivíduos que investem e que não investem em previdência privada) declararam ser brancos, ao passo que 54,25\% afirmaram ser não brancos. Em relação ao sexo, cerca de 60,48\% dos indivíduos que investiram em previdência privada são homens e, obviamente, $39,52 \%$ são mulheres.

Após esse breve resumo descritivo, pode-se, então, analisar os resultados do modelo de probabilidade logit. O objetivo principal foi estimar a probabilidade de as pessoas da amostra investirem em fundos de pensão. A função de verossimilhança convergiu com cinco interações. Pelo valor do teste LR $(5.060,37)$, cujo valor-p foi menor que 1\%, pode-se rejeitar a hipótese de que os coeficientes não são conjuntamente significativos. A Tabela 2 apresenta 
os efeitos marginais (variações na probabilidade) das variáveis sobre a escolha do indivíduo no modelo logit.

Tabela 2 - Efeitos marginais sobre a probabilidade de investir em fundos de pensão pelo modelo Logit

\begin{tabular}{|c|c|c|c|c|}
\hline Variáveis & Nome & Parâmetro & Des. Padrão & Valor-p \\
\hline $\begin{array}{l}\text { Renda } \\
\quad(\text { em mil } R \$)\end{array}$ & $Y$ & 0,0027866 & 0,00011 & $0,000 * * *$ \\
\hline $\begin{array}{l}\text { Escolaridade } \\
\quad \text { (anos de estudo) }\end{array}$ & E & 0,0042978 & 0,00009 & $0,000^{* * *}$ \\
\hline $\begin{array}{l}\text { Sexo } \\
\text { (Dummy) }\end{array}$ & $S X$ & 0,0048838 & 0,00069 & $0,000^{* * *}$ \\
\hline $\begin{array}{l}\text { Idade } \\
\text { (anos) }\end{array}$ & $I$ & 0,0003174 & 0,00003 & $0,000 * * *$ \\
\hline $\begin{array}{l}\text { Raça } \\
\text { (Dummy) }\end{array}$ & $R$ & 0,0051071 & 0,00078 & $0,000 * * *$ \\
\hline $\begin{array}{l}\text { Norte } \\
\text { (Dummy) }\end{array}$ & $N$ & $-0,0039854$ & 0,00104 & $0,000^{* * *}$ \\
\hline $\begin{array}{l}\text { Norteste } \\
\text { (Dummy) }\end{array}$ & $N O$ & $-0,0047072$ & 0,00089 & $0,000 * * *$ \\
\hline $\begin{array}{l}\text { Sul } \\
\text { (Dummy) }\end{array}$ & $S$ & $-0,0008725$ & 0,00093 & 0,346 \\
\hline $\begin{array}{l}\text { Centro-Oeste } \\
\text { (Dummy) }\end{array}$ & $C O$ & $-0,003443$ & 0,00101 & $0,001 * * *$ \\
\hline $\mathrm{PR}(\mathrm{PV})$ no ponto $\mathrm{n}$ & tral & & & 0,0244 \\
\hline
\end{tabular}

Fonte: Resultados da pesquisa

Nota: $* * *$ significativo a $1 \% ; * *$ significativo a $5 \% ; *$ significativo a $10 \%$.

De forma geral, a probabilidade de o indivíduo investir na previdência privada para essa amostra, no ponto médio, foi de 2,44\%. Essa probabilidade reflete o baixo número de brasileiros que poupam para complementar sua renda no futuro em relação ao total da população. Porém, o valor da probabilidade pode ser diferente para classes distintas de indivíduos. Veja-se que um indivíduo branco, da região sudeste, do sexo masculino, que recebe $\mathrm{R} \$ 10.000,00$ por mês, de 38 anos de idade e 15 anos de estudo, pelo modelo, tem cerca de $26,32 \%$ de probabilidade de investir na previdência privada. Já um indivíduo não branco, também com 38 anos de idade, da região norte, do sexo masculino, que recebe R $\$ 1.000,00$ por mês e possui 10 anos de estudo possui remota probabilidade de investir (2,78\%).

Como esperado, a renda e a escolaridade impactam positivamente sobre a probabilidade de investimento. Em média, um incremento de mil reais na renda aumenta a probabilidade de o indivíduo complementar a sua renda em cerca de 0,0028 pontos percentuais (p.p), o que é muito baixo. Já quando o indivíduo estuda um ano a mais, a probabilidade de o mesmo adquirir um fundo de pensão aumenta em 0,0043 p.p. As pessoas que se declararam brancas também possuem maior probabilidade de escolher a previdência privada (em média, com coeficiente indicando 0,0051 p.p. sobre a probabilidade). 
Os coeficientes das dummies regionais mostraram que a probabilidade de os indivíduos do Sul adquirirem um plano de previdência privada não se diferencia estatisticamente da dos indivíduos do Sudeste, ao passo que a probabilidade diminui quando eles são das regiões Norte, Nordeste ou Centro-Oeste.

A Tabela 3 apresenta informações sobre o ajustamento do modelo. Pelo $\mathrm{R}^{2}$ de MacFadden (Pseudo $\mathrm{R}^{2}$ ), observou-se baixo ajustamento do modelo aos dados $(0,1078)$. A especificidade do modelo (percentual de acerto dos indivíduos que não são evento) foi de 99,9\% e a sensitividade (percentual de acerto de quem foi evento) foi de apenas 1,25\%, demonstrando que o modelo é mais robusto para prever não eventos. De forma geral, o ajuste feito permite classificar corretamente mais de $96 \%$ dos indivíduos. Isto é, o modelo possui alto poder discriminatório.

\begin{tabular}{lc}
\multicolumn{1}{c}{ Tabela 3 - Medidas de Ajustamento do Modelo } \\
\hline $\mathrm{R}^{2}$ de MacFadden (Pseudo $\mathrm{R}^{2}$ ) & Resultados \\
Classificação correta $($ cutoff $=0,5)$ & 0,1078 \\
Sensitividade $($ cutoff $=0,5$ ) & $96,35 \%$ \\
Especificidade $($ cutoff $=0,5)$ & $1,25 \%$ \\
\hline
\end{tabular}

Fonte: Resultados da pesquisa

\section{CONCLUSÕES}

A previdência privada tem se tornado uma alternativa cada vez mais utilizada pelos brasileiros em razão da limitação da previdência social em assegurar o padrão de consumo após a aposentadoria, sobretudo para os indivíduos de renda mais alta. Por esse motivo, analisar os determinantes da escolha por investir em fundos de pensão é condição relevante para entender as necessidades individuais e planejar a inserção desse grupo cada vez maior de brasileiros que escolhem complementar sua renda.

Nesse sentido, este trabalho buscou analisar os determinantes da escolha de investir na previdência privada através de um modelo de probabilidade com microdados, no qual os efeitos individuais de variáveis socioeconômicas foram estimados e comparados.

Como esperado, renda e escolaridade são fatores que impulsionam a demanda por previdência privada. Além disso, visto que a idade também é um atributo que eleva a probabilidade de investimento, o número de brasileiros que adquire fundos de pensão certamente irá se elevar nas próximas décadas, uma vez que a expectativa de vida da população tem aumentando consideravelmente. Assim, os gestores, públicos e privados, devem considerar a trajetória de crescimento dessas variáveis para planejar melhor o segmento.

Recebido em: 03-08-2017; Revisado em: 12-10-2017; Aceito em: 25-10-2017 


\section{REFERÊNCIAS BIBLIOGRÁFICAS}

BRASIL. Decreto n ${ }^{\circ}$ 81.240, de 20 de janeiro de 1978. DOU, Brasília, 20 de janeiro de 1978. 1978. . Decreto $\mathrm{n}^{\circ} 81.402$, de 23 de fevereiro de 1978. DOU, Brasília, 23 de fevereiro de . Lei $\mathrm{n}^{\circ}$ 6.435, de 15 de julho de 1977. DOU, Brasília, 15 de julho de 1977.

$2001 \mathrm{a}$.

. Lei Complementar n ${ }^{\circ}$ 108, de 29 de maio de 2001. DOU, Brasília, 29 de maio de . Lei Complementar n 109 , de 29 de maio de 2001. DOU, Brasília, 29 de maio de $2001 b$.

CARVAlHO, F. J.; MURGEL, M. I. Tributação de fundos de pensão. Belo Horizonte: Decálogo, 2007. 227 p.

CASTELAR, I. et al. Uma análise dos determinantes de desempenho em concurso público. Economia Aplicada, v.14, n.1, pp. 81-98, 2010.

COELHO, N.N.A.; CAMARGOS, M.A. Fundos de pensão no Brasil: uma análise dos fatores determinantes para sua expansão na perspectiva dos gestores. $O \& S$, v.19, n.61, pp. 277-295, 2012.

ELLERY JR., R. G.; BUGARIN, M. N.S. Previdência social e bem estar no Brasil. Revista Brasileira de Economia, Rio de Janeiro, v. 57, p. 27-57, jan./mar. 2003.

FENAPREVI, Federação Nacional de Previdência Privada e Vida. Relatório da previdência de 2011. Disponível em: < http://www.cnseg.org.br/fenaprevi/estatisticas/> Acesso em: 12 de julho de 2013.

GACITÚA-MARIÓ, E.; WOOLCOCK, M. (Org.). Exclusão social e mobilidade no Brasil. Brasília: Ipea, Banco Mundial, 2005. 306 p.

GAUDENZI, P. B. L. Tributação dos investimentos em previdência complementar privada. São Paulo: Quartier Latin, 2008. 302 p.

GREENE, W. H. Econometric Analysis. 5a Edição. Prentice-Hall. 2003. 1083p.

IBGE, Instituto Nacional de Geografia e Estatística. Disponível em: <www.ibge.gov.br> Acesso em: 15 de julho de 2013.

LIMA, A.C. Desempenho dos fundos de investimento do tipo previdência privada e sua sensibilidade à variação da taxa de juros. Revista de Administração Mackenzie, vol. 7, n.2, p.61-77, 2006.

MADDALA, G. S. Limited-dependent and qualitative variables in econometrics. Cambridge university press, 1986.

Recebido em: 03-08-2017; Revisado em: 12-10-2017; Aceito em: 25-10-2017 
MORAES, J.R.; MOREIRA, J. P. L.; LUIZ, R.R. Efeito do plano amostral em modelo logístico ordinal: uma análise do estado de saúde autorreferido de adultos no Brasil usando a Pesquisa Nacional por Amostra de Domicílios de 2008. Cad Saúde Pública, v. 28, n. 5, p. 913-924, 2012.

STEFANO, F. Mais velhos e mais ricos. Revista Exame, Vol.45(21), p.70(3), Nov., 2011.

TAFNER, P. Simulando o desempenho do sistema previdenciário e seus efeitos sobre pobreza sob mudanças nas regras de pensão e aposentadoria. Rio de Janeiro: Ipea,Texto para Discussão n 1264, mar. 2007. 39 p.

WEINTRAUB, A. B. V. Previdência privada: doutrina e jurisprudência. São Paulo: Quartier Latin, 2005. $334 \mathrm{p}$.

ZYLBERSTAJN, H.; AFONSO, L. E.; SOUZA, A. P. Reforma da previdência social e custo de transição: simulando um sistema universal para o Brasil. Revista de Contabilidade e Finanças da USP, São Paulo, especial atuária, p, 56-74, dez. 2006. 